\title{
Introduction to the Kritike Special Issue: Philosophical Thoughts in the Age of High Mobility ${ }^{1}$
}

Jinhyoung Lee

$\mathrm{T}$ Today, we are experiencing an unprecedented surge in mobility technologies and a corresponding increase of movement among humans, objects, data, and cultural constructs. Advanced mobile media such as wireless Internet, IoT, small portable devices, as well as renovated conventional vehicles-for example, high-speed trains and autonomous cars-provide us with seemingly unlimited freedom of movement and reflect the unremitting expansion of the global network. However, global mobility disturbance due to Covid-19 emergency triggers the apparent shrinking and blaming of "mobility" on the one hand, but, significantly, encourages us to identify our being mobilized as our supposed "normal status" to be restored, i.e., what we (should) be, on the other. It is the time when mobile technologies condition us and become part of our social life, when motion and movement are embedded in our epistemological, ethical, and aesthetical practices, and when we thus consider not only our existence but also our nature in light of these mobilities. We can denominate this time as the age of high mobility.

In the introduction to his seminal book, Being and Motion (2019), Thomas Nail describes the age of high mobility, noting that,

... more than at any other time in history, people and things move longer distances, more frequently, and faster than ever before. All that was solid melted into air long ago and is now in full circulation around the world, like dandelion seeds adrift on turbulent winds. ${ }^{2}$

\footnotetext{
${ }^{1}$ This work was supported by the Ministry of Education of the Republic of Korea and the National Research Foundation of Korea (NRF-2018S1A6A3A03043497)

${ }^{2}$ Tomas Nail, Being and Motion (New York: Oxford University Press, 2019), 1. 


\section{INTRODUCTION}

Nail's nod to Karl Marx's well-known passage invokes the notion of mobility's rise of status for thoughts sensitive to today's globalized mobilities, although it may be controversial to insist that "mobility climbs to the rank of the uppermost among the coveted values." ${ }^{3}$ The developing and everincreasing global mobility urges us to consider mobility as an unavoidable postulation for those who seek to grabble with contemporary human life, thought, and culture.

As a pioneer of mobility studies, John Urry, a sociologist, proposed 'a new mobilities paradigm' more than ten years ago in order to theorize the social world as "a wide array of economic, social and political practices, infrastructures and ideologies that all involve, entail or curtail various kinds of movement of people, or ideas, or information or objects." 4 While copious ensuant literature concerning mobilities were published hitherto, humanities scholars and philosophers have not paid enough attention to mobilities themselves, although tangentially or sometimes more meaningfully addressing them, as Peter Merriman and Lynne Pearce have pointed out. ${ }^{5}$ This special issue of Kritike, "Philosophical Thoughts in the Age of High Mobility," aims to apply philosophical thoughts to the topic of mobility, assuming the latter not only as a social phenomenon to be investigated but also a key concept necessary to navigate the ontology, ethics, aesthetics, politics, as well as everyday life in our high-mobile world.

In the first paper, "The Political Economy of Global Mobility," Alex Taek-Gwang Lee discusses the political economy of global mobility by analyzing the relationship between the nation-states and globalization, the Empire, highlighting the former's new role in globalizing logistics in the building up of global supply chain of commodities. To this end, he focuses mainly on the ambiguous status of tourists as both consumers (global, moveable) and a labor force (situated obligatorily within a specific territory). As both cosmopolitan consumers of the Empire and members of the nationstates, tourists also can be classified as refugees whenever they lose money or the rights of travel assigned by the nation-states. Thus, he concludes, tourists' ambiguity as representing global mobility's real excursion unlocks the political deadlock of the Empire and the nation-states, underscoring the inextricable relationship between global mobility and the political economy of the Urstaat. His arguments significantly demonstrate how mobility can function as a lens to ponder critically global capitalism's impasse, particularly by staging tourists as its (im)mobile subjects or performers.

\footnotetext{
3 Zygmunt Bauman, Globalization: The Human Consequences (New York: Columbia University Press, 1998), 2.

${ }^{4}$ John Urry, Mobilities (Cambridge, Malden: Polity, 2007), 18.

${ }^{5}$ Peter Merriman and Lynne Pearce, "Mobility and the Humanities," Mobility and the Humanities, ed. by Peter Merriman and Lynne Pearce (London, New York: Routledge, 2018), 2-4.

(c) 2021 Jinhyoung Lee https://www.kritike.org/journal/special issue 2021/j lee1 april2021.pdf ISSN 1908-7330
}

(c) BY-NC-ND 
Meanwhile, Taehee Kim's article, “How Mobility Technologies Change Our Lived Experiences: A Phenomenological Approach to the Sense of Agency on the Autonomous Vehicle," identifies how the human driver attends to driving without being fully engaged in the act in favor of focusing on the autonomous vehicle itself and explores the ethical issues in autonomous driving. While describing the problem of level three (Conditional Automation) from among the six levels of driving automation as classified by the Society of Automotive Engineers International, wherein drivers are exempt from the duty to attend to driving but demanded to engage in a critical situation, he analyses a sense of agency within the domain of kinesthetics, as proposed by Edmund Husserl who described that state as an indispensable condition of feeling responsibility from a first-person perspective because it entailed recognizing the car as driver's extended body or the driver-car as an assembled social being. His discussions guide us to delve into the ethics and aesthetics of post-humans, i.e., human beings as the mobile hybrids (probably) generalized in the age of high mobility.

Li-Qing Qian's paper, "Mobility in Phenomenological Perspective: On Significances of Movement and Quasi-movement in Human Life," figures out the genealogy of the notion of human mobility spanning human corporeal movement to tool-assisted motion, mainly analyzing its multifaceted meanings from a phenomenological perspective. In this paper, Qian classifies its semantic constitutions diachronically as follows: corporeal motion as bodily movement in space and time signifies interactivity, sociality, and freedom; from a topological view of space and motion in the lifeworld, societal motion is deemed the expected and planned action entailing corporeality; as the societal movement in the age of high mobility, motion by transportation involves a social network based on advanced mobile technology and computationalism; modifications of positional changes as quasi-movements in the age of high-tech refer to recorded or even virtually presented appearances of motion(s) mainly in virtual reality; and, finally, modifications of quasi-motion found in mobilities in cyberspace is understood as the unified combination of daily corporeal motion and incorporeal online social action. By highlighting sedimentation and reactivation of its previous significances in the following, Qian facilitates a consideration of "human mobility" not only as a unified sense-complex of different significances but also as a diachronically open-ended conceptual construct.

In their article, "Dangers and Potentialities of the Highly Mobile World: An Ethical Consideration," Ilman Choe and Myungsim Yang discuss the ethical dangers and potentialities of the highly mobile world, redefining Edmund Husserl's critical concepts of lifeworld, home world, and alien world. Understanding the core of mobility as a change of location nuanced 


\section{INTRODUCTION}

by the pragmatic meaning brought about by human activity, they characterize the contemporary world as highly mobile in its frequency and speed. Our nomadic lifestyle and frequent meetings with aliens in this world can give rise to ethical dangers by undermining the stability of the home world, the reliable ground for actions, thereby triggering emotional consequences like depression and anxiety. On the other hand, they insist that our attempts to cope with the dangers can present an overture to new ethical potentialities containing social postulation for an understanding of the other, a gradual universalization of the ethical system, and a new ethical category. By recognizing our lifeworld's highly mobile reformation entailing our unexpected frequent encounters with aliens, Choi and Yang urge us to radically redesign today's ethics in terms of mobile coexistence of home world and alien world.

Wan-I Yang's article, "Homeland, Historicity and Ethical of Image from the Mobilities of Image," also approaches a mobility-relevant ethical issue, like Choe and Yang, but focuses on the ethical of image. In this paper, she argues that the nostalgia for the homeland (Eden/Utopia) not only concerns an actual place denoted by the artists and critics but also a place residing the imagination which carries the expectation for the possibly better, highlighting an inseparable entity of the visible image and invisible beauty in the artist's creation of image. In this regard, the ethic of the image is recognized as the relational care configured by the actual and imagined representations flowing at the core; that is, a colorful universe replete with an interplay of images, the mobilities of image, presents, revealing more possibility of life. For this reason, the process of image creation does not emancipate the artists only from the confinement of reality but also provides them experiences on the fluidity of life, a certain dimension of freedom, forming the image of historicity as revitalizing the subject in process dynamically reshaping the subjectivity. Her arguments demonstrate that incorporating a moment of mobility into image theory can rationalize the latter's mobilization toward image ethics.

Speculation on ethics in relation to mobility is followed by Diego D'Angelo's piece, "To Be or Not to Be at Home. Heidegger and Derrida Reading Sophocles," which focuses mainly on Greek tragedies as conveying absolute hospitality based on acknowledging our constitutive foreignness, thus proposing the impossible definition of the human being as "not-beingat-home" (deinon) as a tension we have to carry. To this end, he supplements Martin Heidegger's reading of Sophocles' texts by Jacques Derrida's reading. First, the uncanny essence of the human being as "the constant not-being-athome" is recognized by Heidegger while considering that people change the world s/he lives in, also that, in this ever-changing world, they will never be at ease or peace. At the same time, D'Angelo continues, Derrida's arguments

(c) 2021 Jinhyoung Lee

https://www.kritike.org/journal/special issue 2021/j lee1 april2021.pdf

ISSN 1908-7330

(cc) BY-NC-ND 
of hospitality are considered supplements to Heidegger's understanding of human beings as foreigners, pointing out that being foreign presupposes hospitality. Despite hospitality's unsolvable paradox, the tension between the idealistic hospitality and the limited expressions of hospitality we inhabit, D'Angelo ultimately contends that hospitality is something the host must achieve independently by acknowledging the not-being-at-home as the uncanny essence of humanity. His discussion can be considered an attempt to actualize and activate hospitality as an ethic, by assuming an essential indistinguishability between natives and foreigners in the context of human beings on the move as typical in the age of high mobility, thereby rescuing the concept from its idealism and paradoxicality.

Finally, Jinhyoung Lee's article, "Mobility Biopolitics and the Aquarium as a Paradigm of Political Space," politically-philosophically discusses modern mobile space by examining the Korean novel, The Aquarium of Love (1939-1940), written and published under Japanese colonialism, in terms of the right to mobility. For him, the colonial government in the Korean Peninsula had fostered a colonial-political mobile space where colonial biopower works via the right to mobility by dichotomically-dividedly organizing society in terms of mobility: citizens with the right to mobility and non-citizens without it. As a paradigm of the space of mobility biopolitics where colonial biopower governs the colonized by assigning them the right to mobility or depriving them of it, also homogenizing them as common fishlike-beings devoid of political rights, he uses the aquarium to argue for the colonial-political space's insubstantiality which originates from categorically excluding political subjects. Consequently, the mobile bare lives, just as fish moving in an aquarium, enables the reader to consider the politics of "more than" the right to mobility by seeking the decolonized-humanized formation of society. By combining mobility studies and biopolitical thoughts, this article provides an alternative paradigm with which to critically examine modern political space as (highly) mobile where people enjoy the right to mobility by trading their political rights for it.

The papers for this special issue have sought to practice thoughts concerning political, ethical, and aesthetical issues considering today's globalized mobility, as well as advanced mobile technologies. Collectively, they reflect that mobility cannot be considered just a social phenomenon; rather it functions as a concept, a lens, and/or problematique helping us find new insights on human lives, thoughts, and cultures on the move. We believe mobility philosophy commits to problematizing, critically reflecting, and suggesting solutions concerning our highly mobile planet.

The Academy of Mobility Humanities, Konkuk University, South Korea

(c) 2021 Jinhyoung Lee

https://www.kritike.org/journal/special issue 2021/j lee1 april2021.pdf

ISSN 1908-7330

(cc) BY-NC-ND 


\section{INTRODUCTION}

\section{References}

Urry, John, Mobilities (Cambridge, Malden: Polity, 2007).

Merriman, Peter and Lynne Pearce, "Mobility and the Humanities," Mobility and the Humanities, ed. by Peter Merriman and Lynne Pearce (London, New York: Routledge, 2018).

Nail, Tomas, Being and Motion (New York: Oxford University Press, 2019).

Bauman, Zygmunt, Globalization: The Human Consequences (New York: Columbia University Press, 1998). 